of peptic ulcer and a falling death rate, ${ }^{11}$ which are unlikely to be due to improvements in treatment.

A major advance in defining susceptibility more rigorously was the discovery by Mirsky and his colleagues ${ }^{12}$ of the predictive value of the plasma pepsinogen level. In $87 \%$ of patients with duodenal ulcer the plasma pepsinogen concentration is greater than the mean of values found in people without gastrointestinal disturbance. This observation is consistent with the view that patients with duodenal ulcer secrete more gastric juice, more acid, and more pepsin than do healthy people. The $14 \%$ with high plasma pepsinogen levels but no history of indigestion are presumably at risk. Using plasma pepsinogen values and psychological testing to identify those with "oral cravings and conflicts" (an extension of Alexander's hypothesis), Weiner, Mirsky, and others ${ }^{13}$ had some success in predicting ulceration in U.S. Army recruits under the stress of basic training.

Nevertheless, the most stimulating work on individual susceptibility to ulceration comes from studies of the effects of immobilization in rats. Extending the original French work ${ }^{1415}$ on constraint and immobilization as a technique for producing ulcers, Ader and his colleagues ${ }^{16}$ at the University of Rochester in New York have defined the conditions in the present and the past that favour ulceration in laboratory rats. A useful summary of this work by Engel has appeared recently. ${ }^{17}$

Almost every rat, it seems, if deprived of food and water and confined in a cage $200 \mathrm{~cm}^{3}$ in volume or less will develop stomach erosions within 24 hours. Less tight confinement for shorter periods allows individual differences in susceptibility, such as the effect of a high plasma pepsinogen level, to appear. Rats were more susceptible if immobilized at night, their active time, rather than in the daytime; if they had been reared in a group rather than alone; if not handled in the preweaning period; or if the mother had been handled while pregnant. Moreover, as Engel points out, these differences in prenatal, postnatal, and current experience may produce an increase or a decrease in susceptibility to a wide variety of other diseases-infections, tumours, or metabolic disorders.

In a further series of experiments Weiss ${ }^{18}$ has shown that rats which are immobilized and given electric shocks will develop more ulceration than those which are not shocked. If, however, an immobilized rat is able to learn from a warning signal that pressure on a panel will avert the shock it will develop far less ulceration than its fellow which had no switch, can do nothing to help itself, and gives up.

It may well be true that ulceration in rats bears only the most superficial resemblance to human peptic ulcer. The equivalents of handling and immobilization within human experience are obscure and cannot be soundly based on crude analogy. But ulceration in the rat in such psychosocial conditions is certainly psychosomatic, and if this research shows nothing else of relevance to disease in man it at least demonstrates complexity: the complexity of past experience in determining susceptibility to disease and the complexity underlying the perception of current experience as stressful.

Engel contends that one important factor contributing to lowered resistance to disease is the loss of the organism's ability to predict and maintain control over its environment. The consequent "fruitless activity" or alternatively" giving up"-adapting Sherrington, he calls these final common paths -may "interact differently with different pathogenic preconditions, and hence constitute variables underlying differential susceptibility to disease in different individuals." For one person with a background of specific genetic influences and life experiences giving up may be more pathogenic; for another or in a different disease process fruitless struggle may be more characteristic and yet more harmful. We have come a long way from the simplicities of go-getters, muddlers, and top dogs.

1 Alvarez, W. C., Nervousness, Indigestion and Pain. Harper, New York, 1943.

2 Dunbar, F., Psychomatic Diagnosis. Hoeber, New York, 1943.

3 Alexander, F., Psychosomatic Medicine. Norton, New York, 1950.

Beaumont, W., Experiments and Observations on the Gastric fuice and in the Physiology of Digestion, ed. A. Combe. Edinburgh, MacLachlan and Stewart, 1838 .

5 Wolf, S., and Wolfe, H. G., Human Gastric Function: an Experimental Study of a Man and his Stomach. New York, Oxford, 1947.

6 Mahl, G. F., Psychosomatic Medicine, 1950, 12, 158.

7 Kellock, T. D., British Medical fournal, 1951, 2, 1117.

de M'Uzan, M., and Bonfils, S., Revue Française d'Etudes Cliniques et Biologiques, 1961, 6, 46.

10 Meade, T. W., et al., British Medical Fournal, 1968, 3, 701.

The Registrar General's Statistical Review of England and Wales. 1966. Part III. Commentary. London, H.M.S.O., 1968.

12 Mirsky, I. A., Futterman, P., and Kaplan, S., Fournal of Clinical Medicine, $1952,40,188$.

13 Weiner, H., et al., Psychosomatic Medicine, 1957, 19, 1.

14 Rossi, G., et al., Comptes Rendus de la Société de Biologie, 1956, 150, 2124.

15 Bonfils, F., et al., Comptes Rerdus de la Société de Biologie, 1957, 151, 1149.

16 Ader, R., Advances in Psychosomatic Medicine, Vol. 6, 1971, p. 1.

17 Engel, G. L., Gastroenterology, 1974, 67, 1085.

18 Weiss, J. M., in Physiology, Emotion and Psychosomatic Illness, ed. R. Porter and J. Knight. Amsterdam, Elsevier-Excerpta Medica, 1972.

\section{Do Little Bellyachers Grow Up to Become Big Bellyachers?}

Recurrent abdominal pain occurs in one out of every nine schoolchildren. ${ }^{1}$ An organic cause for the pain is found in about $7 \%$, so that for the great majority the doctor is left telling the parents that there is no serious cause; he usually goes on to assure them that the child will grow out of the problem. However, as Apley ${ }^{2}$ pointed out, the children with recurrent abdominal pains tend as a group to be more timid, anxious, tense, and fussy than those who are symptom free; they also tend to be over-conscientious and to be bad mixers. In some there is a clear link between abdominal symptoms and specific emotional disturbances, ${ }^{3}$ so that many doctors have worried about the future lives of these children, and the more resourceful have investigated them.

A number of good follow-up studies of children with this syndrome have been completed. Three outcomes are possible for these children as adults, some 10 to 20 years later: they may still have abdominal symptoms; or they may have different "nervous" complaints such as headaches and migraine; or they may be completely free of symptoms. The earlier studies ${ }^{24}$ suggested that children with recurrent abdominal pain were fairly evenly divided among the three groups as adults, though one report ${ }^{5}$ suggested that half became symptom free. More recent work from Denmark presents a gloomier picture. ${ }^{6}$

Thirty-eight children with a mean age of 8 years diagnosed as having recurrent abdominal pain in the years 1942-3 were studied. The diagnosis was made on the basis of at least three episodes of abdominal pain occurring in a period of longer than three months. All the children were fully investigated to exclude organic cause. Thirty years later they were traced as adults, interviewed, and if necessary examined and investigated. The 34 adults traced had a mean age of 36 years. Eighteen had troublesome abdominal symptoms: 11 were considered to have irritable colon, 5 irritable colon plus peptic ulcer, and 2 a definite duodenal ulcer. This incidence 
of abdominal symptoms was more than twice as great as that in a matched control group who had not had recurrent abdominal pains as children.

Interestingly, 11 of the 18 with persistent abdominal symptoms had an extended period in adolescence without symptoms-they grew out of it-and then subsided into it again. The severity of symptoms in 5 of the 18 was sufficient to interfere with normal active life. In addition 11 of the 34 had other symptoms ranging from migraine, headaches, and back pain to "bad nerves." Once again this was a higher incidence than in the control group.

In general it seems that despite sympathetic management in childhood about half the children with recurrent abdominal pain will have troublesome abdominal symptoms as adults. Clearly the syndrome is not as benign as has been suggested. Reassurance and symptomatic treatment may help the child at the time, and also help the family, but it does not necessarily alter the long-term prognosis. ${ }^{4}$ An important aim in the medical care of children is to prevent childhood conditions from interfering with normal development and adult health. At present this aim is not achieved in the management of the large numbers of children with recurrent abdominal pain. There is a need for further research into the causes of the syndrome and for therapeutic trials in the hope that we may be able to prevent little bellyachers becoming big bellyachers.

1 Apley, J., and Naish, N., Archives of Disease in Childhood, 1958, 33, 165. 2 Apley, J., The Child With Abdominal Pains. Oxford, Blackwell Scientific Publications, 1959.

3 Apley, J., and MacKeith, R., The Child and his Symptoms, 2nd edn. Oxford, Blackwell Scientific Publications, 1968.

4 Apley, J., and Hale, B., British Medical fournal, 1973, 3, 7

5 Apley, J., and Hale, B., British Medical fournal, 1973, 3, 7.

6 Christensen, M. F., and Mortensen, O., Archives of Disease in Childhood, $1974,50,110$.

\section{Chronic Paronychia}

Chronic paronychia is a common enough clinical problem, yet failure of response to treatment is a recurrent source of dismay to patient and doctor alike. The condition is most often seen in housewives, nurses, cleaners, or others who often have their hands in water. There is a moderately inflamed swelling over the nail matrix and down one or both sides of the nail; several fingers may be affected. Occasional episodes occur of more acute inflammation and pain, and over the course of time the nail plate itself becomes distorted and sometimes discoloured, usually with transverse ridging.

Recent research interest has been concerned mostly with the microbiological features of the lesion and with treatment directed against the infection, but success in treatment depends more on an understanding of the anatomical and behavioural factors in pathogenesis. The organism most commonly found is Candida albicans, though other Candida species are also common, as are the bacteria of the gut flora; Pseudomonas aeruginosa is responsible for blue-green discolouration of the nail plate; Staphylococcus pyogenes is found especially in episodes of acute and painful exacerbation. ${ }^{1}$ A recent epidemiological study ${ }^{2}$ of the sources and spread of $C$. albicans in chronic paronychia in Israeli women showed that the source of the yeast was usually the mouth or bowel (but not the vagina) of the patient or a member of her family; it also showed that the middle finger of the dominant hand was usually affected first, followed by an adjacent finger or the equivalent finger on the other hand.
C. albicans and the associated bacteria are not, however, primary pathogens, and it is their propensity for colonizing moist skin folds that brings them into prominence in this condition just as it does in submammary or groin intertrigo in obese subjects, or in perlèche due to habitual licking, or to infolding of the corners of the mouth after dental clearance, or simply because of fat cheeks. In all these conditions it is important for the doctor and the patient to understand the parts played by moisture, warmth, and friction in providing an environment suitable for invasion by common and usually harmless organisms.

Patients should be discouraged from fiddling with their nail folds-for instance by detaching the cuticle and pushing it back, thereby opening up a space and introducing organisms at the same time. A similar manoeuvre by the doctor, using a sharpened orange stick dipped in phenol or gentian violet may be therapeutic once the condition has developed, but management should be directed more towards prevention. While it is impossible for affected patients altogether to avoid immersing their hands in water, they should be told to keep such immersion to a minimum. If rubber gloves are worn for washing clothes or dishes they should be removed after about ten minutes and the hands dried, as prolonged wearing gives rise to a very humid, warm climate within the gloves. While the hands are dry, both before immersion in water and as soon after as possible, nystatin ointment can be rubbed gently into the nail folds to act against any yeasts already present and as a barrier against further invasion. Though this may mean more than a dozen applications a day it is important that the patient understands that that is what the doctor intends. During episodes of acute exacerbation gentamicin ointment may be used, with a course of an oral antibiotic such as erythromycin. ${ }^{1}$ Resolution usually takes several weeks or even months, but slow progress should not discourage the patient or her doctor from persisting with treatment and-more important in the long run-with the appropriate preventive measures.

${ }^{1}$ Barlow, A. J. E., et al., British fournal of Dermatology, 1970, 82, 448.

2 Ganor, S., and Pumpianski, R., British fournal of Dermatology, 1974, 90, 77.

\section{Never Forget Syphilis}

Our forefathers saw a great deal of syphilis in all its manifestations, but experienced physicians were well aware of the ability of the disease to deceive and advised their contemporaries never to forget it. Mistakes occurred, because infection was apt to remain latent for years, and when manifestations occurred they were quite likely to resemble those of other diseases. A further handicap, which still persists, is that syphilis was regarded as a disgrace as well as a disease, and physicians who liked and respected their patients suffered in this matter from what Stokes' called "a low index of suspicion." By comparison syphilis is now an uncommon disease, at any rate in Britain, and generations of doctors are unfamiliar with its manifestations and perhaps unaware of its pitfalls. Nevertheless, it still occurs, and its early stages are being found a little more often. With modern ease of communications and the modern tendency towards readier acceptance of intercourse outside marriage it may be that the disease will again become much more common. 